\title{
Smart Questions For The Arabic Language Teacher And The Student
}

\author{
Amal Sabah Rdam Al Tai \\ AL- Qasim Green University, Babil, Iraq
}

\begin{abstract}
The topic of smart questions for the Arabic language teacher and students is one of the important topics, as smart questions are an essential part of the educational process that more than this has become questions of art and a tool that has value in the hands of a skilled teacher, good questions charge the mind and encourage the student to ask himself and ask students each other and ask the teacher has become using the questions as a measure to test the validity of ideas and their acceptance and a way to encourage the learner.
\end{abstract}

This topic has included the following titles

First: The importance of the questions inside the classroom: It is the best way to communicate between the teacher and his students and between the students with each other, as well as stirring the interest of students, motivating them to participate, re-discipline of the naughty students, and drawing the attention of students to listen.

Second: The skills needed to ask smart questions: Quietly ask the question so that everyone can hear it and wait for three to five seconds after asking the question. Also, distribute the questions to all students (strong and weak) and encourage students to answer by using positive reinforcement such as (well done, excellent).

Intelligence is among the apparent phenomena that do not need to be defined. However, the scholars who studied this topic differed about the nature of intelligence, and as they differed in its definition, some have known it as the ability to acquire and use knowledge to solve problems and adapt to the world. Several studies have been conducted to test and measure intelligence. Wechsler developed a test to measure the $1 \mathrm{~K}$, where he divided a special measure for the intelligence of adults and adolescents, and they are among the most famous American standards. Studies have proven that poverty affects IQ as children who come from social classes or high and all of this is due to factors specific to heredity and the social and economic level.
The researcher have developed a number of models to explain emotional intelligence, including the Golman model, which sees that emotional intelligence is a group of the diverse capabilities that individuals possess and are necessary for success in different aspects of life that can be learned and improved, and includes emotional knowledge, emotion management, enthusiasm, perseverance, motivation, self awareness, emotions of others, and awareness of social relationships and stresses Golman said his concept of verbal intelligence, mathematical logical intelligence, linguistic intelligence, lyrical visual intelligence, motor physical intelligence, musical rhythmic intelligence, and natural intelligence.

There are several methods for evaluating school achievement Editorial tests that include essay testing, short answer questions, pairing or interview questions, and graphic tests.

\section{Smart questions}

The traditional method of teaching makes the student passive recipient due to his dependence on lecture, diction, command and prohibition. Modern education had to make the alternatives that you see more effective and more effective for achieving successful teaching and learning to build a sound scientific personality. One of the alternatives was the question and dialogue to find a productive interaction and tomorrow the use of questions is an essential part of The educational 
process, but more than that, the questions have become an art and management that has value in the hands of a skilled teacher. Good questions charge the mind and scarcity the student to ask himself and ask students each other and ask the teacher and the use of questions has become a measure To test and validate the ideas, and a way to spread the learner and finally to achieve the goals of the teacher in a short.

\section{This topic included the following titles:}

First: The importance of the questions in the classroom

A- The best way for the teacher and his students to communicate with each other.

B- Arousing student interest and motivating them to participate

C- Assigning students 'prior knowledge before starting the lesson

D- Directing students 'thinking towards higher levels of thinking

E- Re-discipline the riot students by asking them to justify their behavior

F- Attracting the attention of students to listen and focus, especially students who suffer from poor attention.

Second: The skills needed to ask class questions

1- Quietly asking a question so that everyone can hear it then choosing a student to answer

2- Waiting for three to five seconds after asking the question before allowing any student to give the answer.

3- Distributing questions to all students (the strong and the weak)

4- Encouraging students to answer by using positive reinforcement such as (well done, excellent, good, blessed).

5- Avoid excessive praise and unwarranted praise, such as saying what a great answer is, or you say this is the best answer I've heard! Then participation decreases.

There are basic principles that must be observed when using classroom questions, and they are:

First: Drafting and clarity

The teacher formulates questions so that the expectations of their response to the student are not continuous questions.

\section{Second: - Adapting the questions}

The teacher adapts the questions according to the class and adjusts these questions according to the students 'language and their level of abilities. The questions must be understandable and the teacher must adapt the questions to meet the individual needs of students

\section{Third: - She follows the questions}

The teacher uses the questions in a sequential and sequential manner, and he also asks questions according to an arranged pattern indicating a clear and purposeful strategy in asking the question.

\section{Fourth: - Balance}

The teacher balances between the grouping and the encouraging questions, and the teacher uses questions with appropriate levels to achieve the objectives of the lesson, and the teacher must consider the purpose that the class wants to achieve.

\section{Fifth: - Participation}

It is that the teacher directs questions that raise a wide range of student participation, and that the teacher encourages students to participate in the answer in terms of providing an opportunity for all students to answer, whether they are volunteers or non-volunteers, and the teacher redirects the questions that were answered first to other students so that the interaction between the student and another is encouraged.

\section{Sixth: Waiting time}

The teacher uses the waiting time after asking the question and after answering the students, especially during the discussions. The teacher pauses at least three seconds after asking the hyperlinks to allow students to comment continuously.

\section{Seventh: Students' questions}

The teacher asks students to initiate questions, and he also encourages students to put questions that are closely related to the topic, stimulates thinking at the hyperlinked level, and asks questions that need thinking.

\section{Third // properties of a good question}

Good questions have many characteristics, the most important of which are: 
1- Truthfulness: - That is, it measures what was set to actually measure it and does not go outside the framework of the lesson and in setting objective objectives by the teacher, for example, the teacher raises a physical question, and he measures the student's linguistic ability

2- The question should be from the students 'level of thinking and within the limits of their experiences, not a sacred question.

3- Clarity: The question should be clear, unfamiliar with the students, that it be as short as possible and that it revolves around one idea in order not to distract students 'thinking.

4- Accuracy: That the question be accurate and there is no room for interpretations, interpretations and interpretations that are far from required.

5- That the question evokes students 'thinking.

All this from the premise that a good question is half the answer.

\section{Fourth // Motivating students to ask questions}

There are several factors that motivate students to ask questions:-

1- Encouragement: Participation is a factor of curiosity, internal instinctively and requires a little effort from the teacher to motivate students to discuss, exchange opinions and ask questions by encouraging them to speak or providing materials that stimulate students' curiosity and provide them with the opportunities for exploration, which leads to asking questions when they encounter any specific problems.

2- Model: The questions that the teacher raises are considered a model, and students should be introduced to how to ask good and creative questions. A question can also be asked, for example, weekly that stimulates students to think and leads later to students also trying to participate in developing questions.

3- Class atmosphere: Students ask questions when they feel the freedom to share their thoughts away from dread or hurtful criticism or ridicule, and the teacher must reinforce curiosity through praise and encourage students who invent good questions, and there must also be a wide scope for expressing opinion without fear.
4- Evaluation: We can ask students to ask their questions as another way to evaluate what they have learned, for example, to write students questions that they consider important for a specific topic they have studied and compare these questions with the goals set by the teacher as well as note the quality of these questions.

\section{First: - Intelligence}

It is the ability or ability to acquire and use knowledge of all problems or to adapt to the world (Anima Woolfock, 2009, p. 376).

Al-Obaidi and Al-Jubouri mentioned (measurement and presentation in education and division) a number of definitions of intelligence for some scientists, including them.

Bert defines intelligence as: the general innate cognitive ability

1- Rex Knight has defined: the ability to discover the appropriate qualities of things and their relationship to each other.

2- Pinter sees intelligence: that it is the individual's ability to successfully adapt to new signs in life.

3- Kehler sees that intelligence: is the ability to gain insight into humans and animals. (Al-Ubaidi and Al-Jabouri, 1970, pp. 204-205) Abdul Hadi mentioned in his book (Introduction to Educational Measurement and Evaluation) a number of definitions of intelligence for some scholars, including:-

Gates has defined intelligence as: a system of abilities to learn and perceive indirect public facts. 4- As for Wexler, it is seen that intelligence: the individual's total ability to work in order to think rationally and realistically with the surrounding environment (Abdel Hadi, 2002, p. 38) and there are other definitions of intelligence, including

Intelligence is the general ability that an Intelligence is the general ability that an individual appears to be able to establish relationships and interconnections (Spearman).

Intelligence is the ability to confront right judgment, right understanding and right thinking (Binet).

5- Intelligence is the ability to confront emerging situations and visualize new responses 
constructive and resilient (Thurston) (Spring, 2010, pp. 379-380).

Zayour has defined intelligence: it is a group of abilities and qualifications whereby we better dominate its tasks, our professional lives, and our lives in general, and it produces indications in two ways: understanding and perception on one hand, and its extension and production on the other hand (Zayour, 2009, 253).

\section{Second: - The meaning of intelligence}

\section{A- The philosophical meaning of intelligence}

Searle Burt, the famous English psychologist, indicates that the term intelligence refers to the Latin word coined by the ancient Roman thinker Cicero (first century BC). On this basis, the study of mental activity was not confined to psychologists but was taken up by philosophers before them (Rabi ', 2010, P. 38).

The philosophers' approach to studying the concept of intelligence was introspection, provided that the philosopher himself noticed while he was thinking or any other activity, and then take note of his self-observation after that (Al-Sheikh, 2011, p. 74).

The first attempt to study mental activity was at the hands of the philosopher Plato, where Plato divided the human soul into three components (mind - desire - anger, which corresponds to contemporary psychology: perception - emotion tendency) and Plato likens the forces of the mind to a vehicle driven by a skilled driver (the mind) And dragged by two horses are the will (the tendency) and the desire (desire), while Aristotle reduced the concept of Plato in two basic appearances: cognitive reason and emotion (circumcision, Abu Saeed, Karaki, 2010, p. 149).

\section{$B$ - The biological and physiological meaning of intelligence}

This meaning belongs to the English scientist (Herbert Spencer) (late nineteenth century) where (Spencer) described life as the continuous adaptation of internal forces with external forces and adaptation in the animal by instincts and adaptation in humans thanks to intelligence, meaning that intelligence is what is celebrated
This environment is characterized by variables and complexities (Rabi ', 2010, p. 381).

These scientists see that the more complicated the nervous system of the animal the more it increases its ability to adapt to the environment and learn new business, and this of course indicates that they consider intelligence to be inherited and not acquired, so we conclude from this that physiological psychologists see that the more the nervous system complicates and branched out to the organism The more intelligent it becomes, and this explains that humans are the most intelligent living creatures (circumcision, Abu Saeed, AlKaraki, 2010, p. 150).

Given that Cause Neserar was largely influenced by his outlook on development, he decided that during the development of the animal kingdom, a difference occurred in the basic cognitive ability that turns into a hierarchical organization of more specialized capabilities, sensory, associative, and cognitive, as is the case of the tree trunk (Sheikh, 2008, p. 57).

\section{C- The social meaning of intelligence}

Man does not live in a vacuum but rather lives in a society that is influenced and influenced by him, and because each society has its own civilization, traditions and customs, so scientists have sought to link intelligence and some factors that are the product of social interaction (circumcision, Abu Asaad, Al-Karaki, 2010, p. 151), an example of which is an idea ( Thorndike) says that there are three types of intelligence: abstract, mechanical, social and social intelligence: is the ability to understand others and deal with them efficiently (Spring, 2010, p. 382), while abstract intelligence: is the ability to address verbal and symbols, and mechanical intelligence: is the ability On the handling of objects and material as it appears in the skills Mechanical medicines (Sheikh, 2008, p. 58).

\section{Third: the unit of measurement of intelligence}

IQ: It is the numerical value that enables us to compare the mental age of an individual with his chronological age (circumcision, Abu Asaad, AlKaraki, 2010-2011, p. 161). He knew (Anita Wolfock) IQ: it is the degree that compares 
mental and time ages (Anita Wolfke, 2009 , P. 377) In order to calculate the IQ, individuals can be divided according to the distribution of intelligence into the following types:

1- The percentage of intelligence from (140 or more), who are very highly intelligent and geniuses, and their percentage is $1 \%$ of the world's population (scholars, philosophers).

2- The intelligence percentage is from $(120,139)$ who are highly intelligent and gifted and their percentage is $11 \%$ of the world's population (some scholars, creators).

3- The IQ is from (90-109), they are average, and they are $46 \%$ of the world's population (they are the general public).

4- The IQ is from (80-89) and they are below the average and $15 \%$ of the world's population (individuals who suffer from some mental illness).

5- Intelligence ratio from (70 - 79) and they are the boundary between ordinary and mentally handicapped and their percentage is $6 \%$ of the world's population.

6- The IQ is less than 70, and these are mentally retarded, and their percentage is $3 \%$ of the world's population (mentally unstable) (Al-Khatatna, Abu Asaad, Al-Karaki, 2010, p. 162).

\section{Skew IQ}

It is a score that depends on the statistical comparison of an individual's performance with the average performance of others in the age group (Anita, Wolfock, 2009, p. 377).

\section{Creativity and intelligence}

The results of the studies generally showed that there is a positive relationship between creative thinking and mental processes, as it was found that individuals with high abilities who mean creativity tend to have an above average level in terms of intelligence and this means that a certain level of intelligence is necessary to provide creative responses as for individuals with low abilities from Where intelligence tend to have low capabilities of creativity (Ryan, 2006, p. 38), and there is almost a general agreement that in order to achieve a high degree of creativity it is necessary to provide a degree of intelligence, the minimum required by scientific creativity according to what some researchers see is equivalent to the proportion of global intelligence Which It can help with scientific creativity, it is located at (125) degrees of intelligence, while the minimum for arts can be at the level of intelligence (95 - 100) degrees, while the upper limit is at (115) degrees (Rayan, 2006, pp. 38-39).

\section{Achievement and intelligence}

The classic theory of intelligence assumes that human intelligence is monolithic and that one can be described as possessing one intelligence that is controllable. This theory has had a marked impact on educational practices. Perhaps it is still common to use codified IQ tests to provide various special programs for children, but contemporary research She explained that intelligence is not a static structure so that it can be measured and quantified with a meaningful quantity, but rather it is an open dynamic system that can continue to grow throughout the human life, because intelligence is adjustable by facilitating teachers to learning experiences and interactions between them and their students, and Diamond is a specialist In neuropsychology, the human brain can change and improve with use, and the theory (brain flexibility) suggested that environmental conditions, personal counseling, and the way individuals think and act actually lead to changes in the body, brain, and intelligence. Strenberg suggested three types of intelligence are: high creative intelligence They are characterized by initiation, creative activity, and discovery. As for students who are characterized by scientific intelligence, they can apply the information you know and employ it in real life situations, and intelligence and analytical intelligence can be measured using similarities that require comparisons and variations between Words, symbols and patterns (Allam, 2007, p. 63). Cognitive mental level

Scientists indicate that the more complex and difficult mental processes, the more the mental differences that exist between different individuals have increased, and studies have shown that both interfaces and Henry's extent of the difference in the behavior of individuals with respect to the 
existing processes between people's thinking more than the differences between their sensory distinction and Thorndike research indicated that the difference of differences Reasoning in acquired mentalities than in innate aspects (Melhem, 2011, p. 285).

\section{Increase and improve intelligence}

Most specialists in psychology in general and intelligence in particular tend to accept the first theories in the concept of individual intelligence and its stability. There are serious researches in Britain and the United States of America, Zvenzuela, indicating the possibility of raising the level of intelligence among individuals through specific programs directed towards that, and this means setting Programs to teach intelligence with the aim of increasing, and a book has been issued for the psychologist Arthombi entitled Intelligence that can be learned, and there are even ideas and discussions revolving around the possibility of biological intervention in the components of genetic intelligence.

James Flynn, one of the most respected scientists in New Zealand, has conducted studies on the change in IQ ratios from one generation to another. It has been found that the IQ of individuals in 14 western countries, including the United States of America, increased between 15 to 25 points in one generation, more specifically. This increase reached 21 Point during 30 years, in the inherited fluid intelligence that is affected by cultural factors. The increase reached (14) points in 45 years. For example, the study indicated that the annual increase in the percentage of liquid intelligence ranges between $4-1.1$ points annually in Germany.

Most studies indicate the possibility of increasing the IQ, and the special programs offered by educational and psychological institutions for gifted students are only evidence of the conviction of the possibility of increasing the intelligence of individuals (circumcision, Abu Asaad, Al-Karaki, 2010, p. 166).

Fluid intelligence: is the ability or capabilities to acquire and use knowledge to solve problems and adapt to the world (Anita and Wolfock, 2009, p. 376).

Likewise, it refers to intelligence that relates to specific mental processes, such as classification numbers, letters or names according to a specific code, where the individual is required to perform new or unusual mental processes or that there is a relationship between things that are not related to them at all (such as testing numbers codes in The Wechsler Intelligence Test and the Beta Intelligence Test, which is assumed that this flowing intelligence depends on the growth of the nervous system as it is freed from the impact of culture or the environment (Rabi ', 2010, p. 290). Crystalline or crystalline intelligence: is the ability to apply culturally agreed-upon problem-solving methods (Abita, Wolfock, 2009, p. 376), and also it is meant that is related to the use of the outcome of information that an individual has in solving problems and in issuing judgments and this outcome of information is acquired It depends on culture and education (Rabi ', 2010, p. 390).

\section{Emotional intelligence}

As the ability to monitor feelings, self-emotions, and feelings of others, Golman knows: It is a group of diverse ability that individuals and crisis possess to succeed in various aspects of life that can be learned and improved, and includes emotional knowledge, emotion management, enthusiasm, perseverance, motivation, awareness of others 'emotions and awareness of social relationships (Saeed, 2008, P. 81).

Golman performs that his concept of emotional intelligence is based on Gardner's concept in multiple intelligences and is determined by the following:

\section{Self - Intelligence}

\section{Social Personal Intelligence}

Personal personal intelligence is formed by forming a sincere and conscious model of the self derived from thinking beyond knowledge and the use of this ability in life. This intelligence is represented in the work of doctors, psychologists and social workers. Social personal intelligence is achieved through establishing relationships, 
communication and social cooperation between people. (Saeed, 2008, p. 82).

Theoretical trends in emotional intelligence mo dels

Researchers have diversified attitudes in defining the concept, skills, and dimensions of emotional intelligence within various models, including:

\section{A Goleman Model of Emotional Intelligence}

1) Emotional Knowledge: It is represented in selfawareness and recognition of a feeling of its occurrence and monitoring of emotions and emotions and their understanding. Self-awareness is the primary dimension in emotional intelligence.

2- Emotions management: Includes the ability to deal with emotions and manage them appropriately, calm the soul and get rid of anxiety and negative feelings.

3- Motivating oneself, that is, directing emotions to achieve a specific goal for the individual, and for the individual to be a source of motivation for himself.

4- Realizing the emotions of others, which includes the ability to sympathize with others, knowing their emotions and the ability to pick up emotional signals for others and build this ability on the basis of awareness of emotions and is a necessary human skill in leadership actions.

5- Social Relationship Management: This field requires social sufficiency and requires influencing skills to manage and control the emotions of others. This dimension is an important requirement in senior leaders and businesses that require extensive communication with society (Saeed, 2008, pp. 81 82).

\section{-Parowan Model of Emotional Intelligence}

1- The internal personal components: It consists of a group of competencies that help the individual to deal with himself successfully, which is selfawareness, assurance, self-esteem and independence

2- The components of interpersonal relationships consist of a set of competencies that help the individual to establish successful personal relationships and have a positive impact on others and include empathy, social.
3- Adaptive components: It is a group of competencies that helps an individual to successfully adapt to the realities of life and the requirements of the surrounding environment, which is a reality test, flexibility and problem solving.

4- Stress management components: It is a group of competencies that helps an individual to manage stress, impulse resistance, and selfcontrol, and includes stress tolerance, psychological pressure, and impulse control.

5- General mood components: It is a group of competencies that helps an individual to perceive and change his mood and includes optimism and happiness (Saeed, 2008, p. 83).

Emotional intelligence skills

1-Self-awareness: which consists in identifying self-made emotions and making them sound moment by moment and identifying feelings and tendencies in major life issues such as learning, marriage and work.

2- Managing emotional life in situations of distress, stress, anxiety, and mitigating failure and frustration.

3- Activating the self-motivation, which is the skill of directing emotions towards goals of importance to one, while controlling the ability to self-control emotions in order to reach a high degree of productivity and innovative performance through self-motivation and raising the level of hope of individuals.

4- Knowing the emotions of others, which includes the ability to empathize, understand and be sensitive to indicators of the feelings of others and their emotions.

5- Effectiveness of directing relationships with others such as leadership and ten cases and dealing with the news through representing the basic social skills (Said, 2008, p. 84).

\section{Multiple types of intelligence}

1- Linguistic intelligence: It is the ability of an individual to be sensitive to written and spoken language and the ability to learn and use it to achieve specific goals and to use it orally or in writing (Nofal, 2008, p. 99) or is the ability to generate language and language structure that 
includes poetry, story writing and the use of metaphors (circumcision), (Abu Saeed, AlKaraki, 2010, p. 154).

2- Logical or mathematical intelligence: It is the ability to logically think and simulate and deal with numbers and create numerical patterns (circumcision, Abu Saeed, Al-Karaki, 2010, p. 155), and to build abstract relationships that take place through inferred symbolism and this type of intelligence we find developed for scientists from physicists And those interested in mathematics and computer programmers (Nofal, 2008, p. 98).

3- Lyrical or visual intelligence: It is the ability to create mental images, visualization, visual arts and architectural design (circumcision, Abu Asaad and Karaki, 2010, p. 155), and this type of intelligence requires a degree of sensitivity to the color, font, shape, nature, field and relationships between these elements. This type of intelligence is for sailors, pilots, sculptors, and painters (Nofal, 2008, p. 98).

4- Physical or motor intelligence: It is the ability to use sensory and motor skills and coordination between the body and the mind through working to find a perfect consistency of the various movements performed by the entire body or part of its limbs (Nofal, 2008, p. 98). Examples include the ability to perform manual work. With skill and ability to control and coordinate movements (Al-Khattinah, Abu Saeed, Al-Karaki, 2010-2011, p. 154).

5- Rhythmic musical intelligence: It is the ability to distinguish sounds and tones (Al-Khattinah, Abu Asaad, Al-Karaki, 2010, p. 155), and some children appear in this performance of playing at an early stage of their life and this is what leads them to expression and innovation (through music as is the case For musicians and playlists (Nofal, 2008, p. 99).

6- Natural intelligence: It is the ability to distinguish plants, animals, and other environmental components such as clouds, soil, and minerals (circumcision, Abu Asaad, Karaki, 2010, p. 155).
This type of intelligence can be distinguished from farmers, animal husbandry, geologists, and archaeologists (Nofal, 2008, p. 100).

\section{Principles of multiple intelligence theory}

1-There is no one constant intelligence that we inherited and cannot be changed.

2- Each person possesses a number of intelligences, not one.

Intelligence can be developed by individuals

3-Teaching methods of children must be consistent with their intelligence

4- Strong intelligence can be employed by the individual in developing weak intelligence (Katame, 2010, p. 57).

The application of multiple intelligence theory in teaching

As a teacher, I can apply multiple intelligence in the following areas- :

-1In organizing the course material, and reformulating it.

-2In my teaching plans, my methods, and their diversity to include multiple intelligences.

-3In the duties and tasks assigned to my students or selected by my students.

-4 In the working papers he prepared.

-5In the classroom and non-classroom activities that he organized.

-6In the evaluation calendar and through my class questions.

-7In exams and through exam questions (Obeidat, 2013, 224.(

\section{Intelligence tests}

1- Cigan test, developed in 1866 , to discover the weak of minds. It consists of 10 pieces of wood. It is required to place them in a special wooden board to stop codified conditions.

2- Knox test (4) cubes and 10 pieces of wood to make a picture of a ship that was set in 1914 and was modified.

3- Pinter-Peterson. It is similar to the previous two tests or derived from them by creating 15 questions and modifications were made to it.

4- The Kohas cubes drawing test, consisting of a set of identical and colored cubes that are placed 
in designs and the child is asked to draw them, using the Stellenford-Benich test to diagnose the mentally different, set in 1923.

5- Porte's Maze was established in 1914 to measure intelligence from 3 years to 18 years and it consists of a series of mazes and asks the child to follow a method with a pen without departing from the passages or return and gives the person four attempts once for two people or the measurement of individuals, i.e. do not depend on one measurement (the Imam And others, D.T., pp. $286-287)$.

\section{The Wechsler Bellevue test of intelligence}

It consists of a special measurement for children from the age of fifteen and the other scale is a supplement to this scale and is suitable for measuring the intelligence of adults and adolescents, and it is one of the most famous American standards and a person and Kassler deficiencies that were experienced by the available standards at that time, including a clearer scale, this scale consists of (11) sub-tests divided into Two sections, verbal measurement and includes six tests: general information, general understanding, mathematical reasoning, analogies, and numbers and vocabulary return. As for the scientific scale, it includes five tests: number codes, image completion, cubes drawings, arrangement of images, and grouping of things (Emirate, 2014, pp. 48-49) . (Wexler), (Raven), (Heim) and (Murray House) found various types of intelligence tests for adults. Children in early childhood roles vary in the speed of development and change quickly what they accomplish from one condition to another, which leaves only a small basis for what It is possible from mental differentiation. As for adults, the factor of complexity is represented in experience and acquired skills. Indeed, adult intelligence exceeds children's intelligence by complicating it by intertwining with acquired abilities, and this opens a door to ask about the amount of what these acquired abilities gained from innate preparations (McFland, 1994 , P. 67

The Wechsler exams consist of three:
1-The wppsi test of children's intelligence for preschool age ages $4-6,6$

2- The wisc test for males of ages between 6.6 16 years.

3 - The wais test for the intelligence of adults aged 16 years and over

Each of these three groups consists of a set of subtests ranging between 11-12 tests and within each test 14-16 questions which are divided into verbal and performance tests (Imam, Abdul Rahman, AlAjili, DT, p. 279).

The Wexler Scale for Adult and Adolescent Intelligence is distinguished by several advantages over the Stanford test - the most important of which is:

The vocabulary of the test is more suitable for adults

- This measure dispensed with the age levels and thus took another kind of criteria instead of mental age, as it is possible in this measure to calculate the IQ directly without the need for mental age.

- This scale is characterized by giving 3 degrees of intelligence (a degree of verbal intelligence, a degree of scientific intelligence, a degree of total intelligence) and therefore it is used a lot for clinical purposes besides measuring intelligence (Ghabari, Abu Shaira, 2014, p. 158).

Steps to analyze exam questions

1) Reading the content of the Arabic grammar book for the sixth scientific and literary grade, a good reading of knowledge of its content and all subjects.

2-Read the questions well and answer them appropriately.

3- The question that contains several branches treats each branch as an independent question.

4- Matching the questions with the criteria approved by the researcher.

5- Unpacking the results of the analysis in the tables within the approved criteria for analyzing the questions.

6- A percentage of matching for the textbook abuse: It is a ratio between matching the questions of examination papers with the questions or exercises found at the end of each topic of the 
textbook, as the exam questions were analyzed by distributing them in the following patterns.

-Questions contrary to the book's questions: The examination questions papers were analyzed for the scientific and literary branches by giving duplicates and then extracting the percentage.

- -Direct questions and indirect questions: Direct questions, which are questions that take their phrases as a text from the text of the textbook and in a form that has been reformulated and arranged in a new situation in the same sense and called (understanding questions) (Barakat, D.T., p. 52).

There are several methods for evaluating school achievement:

\section{First: - Written exams}

It is the exams that are intended to evaluate the academic achievement of students and students at the end of the academic period and in the examinations of transportation and public certificates, and it is considered one of the most important means of evaluating achievement and determining the level of students in this achievement (al-Gharib, 1985, p. 75).

\section{Types of written exams}

A- Essay test: It is a test with a free answer and it is sometimes called structural or traditional tests because these tests give the student the opportunity to issue his own answer and how to organize the answer and its composition, it helps to measure specific complex goals such as innovation, organization, complementarily between ideas and expressing them using HYB Among the weaknesses of this type of test are the lack of coverage of all of its questions for the whole subject and the effect of its correction by the subjective factors of the corrector (Samara et al., 1989, p. 27).

\section{advantages}

It does not spend much effort in preparation and it is appropriate to measure the cognitive aspects of behavior such as remembering, understanding and analyzing. It is possible to judge the expressive ability of students and judge multiple capabilities, including problem solving (Qurah, 1975, p. 39).

Disadvantages

- Not all material is covered1
2- You need written ability

3- The self-debugger is included

4- The student may deviate from the substance of the topic

5- The long time you need to think and answer

-6)Varying interpretations made by students (Abdel-Hadi, 2002, p. 56

The article questions are divided into two types Restricted answer questions (limited article) These questions place restrictions on the required answers and specify the content of the article with its narrow limits such as (Answer more than two lines, specify your answer in five lines, number, custom, reason, rank in a list, and it is required for this type of questions To be comprehensive in the subject and clearly defined, with setting key points for the questions that determine the course of the student's response.

advantages

1- It gives the student the freedom to answer more than the objective questions.

2- A personal opinion is requested in the answer, which increases the student's confidence.

advantages

It has a relatively small value to measure its ability to organize and integrate, which makes it limited to measuring goals from the levels of understanding, application and analysis. Moreover, its correction is affected by the subjective factors of the corrector (Samara et al., 1989, p. 128).

\section{B- Free answers questions (extensive article)}

These questions give the student the freedom to determine the form of the answer and its scope and demonstrate his proficiency in organizing, synthesizing, composing, evaluating, and clearly approaching the solution of the problem. These are all important education goals that cannot be measured with other types of paragraphs tests (Abu Alaa, 1987, pp. 158-160).

The basics of writing essay questions

1-Using essay questions to measure complex learning goals, which are from the category of installation and evaluation, such as planning a 
specific process or criticizing a story or experience and evaluating it.

2-Linking essay questions to the learning goals to be measured

3- Formulating the question in a manner that presents the required to the student in a specific and clear manner

4- Not being able to choose from questions

5- Estimate the appropriate time to answer each question (Imam et al., 1990, pp. 52-53).

\section{Second: objective tests}

it is called the quiz tests compared to the essay tests, and it is known in the name of objectivity for its accuracy, reliability and lack of effect of correction by the self-correcting factors of the correction, and it is on multiple types, the most famous of which is right and wrong, multiple testing, interview, and completion, and with the features that are characterized by objective, comprehensive and high in Factors of honesty, consistency, ease of application and correction, but their preparation is difficult and limited to measuring some complex educational goals such as arrangement and evaluation, as it opens a field for cheating and guessing by students, therefore it is advised not to use them alone without tests pans But thanks to the combination of the two types, and this is due to the nature of the course material (Abu Libdeh, 1979, p. 275).

\section{Types of objective tests}

\section{-1Correct and incorrect questions}

The greenhouse and error test consists of a number of phrases, some of which are true and some of them are wrong, and the student is asked to remember if the phrase is correct, then he will mention the word "yes" or "right" or "correct" or a sign $(\sqrt{ })$. But if the student sees that the phrase is wrong, he will mention Alongside it is the word "no", "(false)", or "X". This type of test is used to measure simple cognitive goals from the category of remembering and memorizing, as it is not used in measuring the higher mental abilities such as application, analysis, composition and evaluation. advantages
It is more comprehensive in terms of the amount of content of the subject matter that it can cover at a specific time. It is also easy to correct. Answers to this type of question can be estimated with complete objectivity.

\section{Disadvantages}

Guessing that chance and guessing play a big role in it, a student who does not know the answer has an opportunity to test the correct answer randomly (50\%), and most of the paragraphs of right and wrong relate to simple facts and surface information because it is difficult to design paragraphs of this type that are valid for measuring understanding and application (Abu Libdeh, 1979, pp. 291-292).

\section{2- Multiple test questions}

This type of test presents a problem and then presents several alternatives, usually four alternatives, one of which is the correct answer to the question, and the answer is either by choice.

-The correct answer from other answers is wrong and is known as searching for the right thing.

- The incorrect answer is one of the correct answers, and it is known as the search for a mistake.

The most important or strong answer is known to search for the most important (Khater, 1989, p. 64).

The advantages of multiple choice paragraphs

The element of guesswork is less than right and wrong questions

- It helps to measure the student's ability to distinguish between correct and wrong judgments.

- Reliability and validity, much more than other types.

- It can be used to measure different cognitive goals, such as remembering, understanding, and applying.

Its results can be analyzed statistically easily-

Easy to correct-

Disadvantages

- Preparing it requires a great effort from the teacher and requires him a long time to review the 
study material to test the paragraphs and prepare them.

It needs a lot of expenses to print-

-The student needs a lot of time to read questions and this is a waste of his time for the exam

The scope remains open to fraud and speculation If you do not prepare elaborate numbers, they are of low sincerity, with little coverage of the subject matter, and are limited to measuring the goal of remembering and not other cognitive goals (Samara et al., 1989, pp. 79-81).

There are a set of rules and principles for preparing multiple test questions, including:-

1) The test items should measure an educational goal and not be concerned with measuring boring details.

2) Each paragraph should present a specific and clear problem

3) Avoid the negation formula because it reduces the ability to achieve educational goals

(44) The necessity of homogeneity of paragraphs in terms of length or content

(5The paragraphs should be randomly distributed so that the student does not have the opportunity to guess (Megawar, 1974, p. 52).

\section{3- Completion questions}

The completion test clause consists of an incomplete sense of the news sentence, and the student is asked to complete it by placing the appropriate word, semi-sentence, symbol or numbers, and this form is one of the most common forms of paragraphs and questions that restrict the student's freedom to formulate the answer (Odeh, 1999, p. 158).

\section{Benefits of supplementary questions}

1- These essay questions are more objective in that guesswork is less than others.

2- It is distinguished from essay questions as being more objective and correcting them easier.

3- We can cover a larger area of the subject matter if we compare it to traditional pans.

\section{Disadvantages}

1- Less objective than other patterns Objective questions

2- It requires the effort and time of the proofreader to correct due to the multiple responses that need to be read by the proofreader (Samara et al., 1989, p. 89).

\section{4- Short answer questions}

Tests with short answers are very similar to the completion tests, and it is one type of questions and the only difference between them is that the question of completing is an incomplete phrase and the meaning is only clear in the word complementary to it, while the short answer test is a complete phrase in the form of a question and is required to answer it with a short answer and in general a longer From an answer, especially if the paragraphs appeared in the form of a question instead of a complete picture of the meaning (Odeh, 1999, p. 158).

\section{5- Pairing or interview questions}

Also called matching tests and this type of paragraphs is a modified image of the second poor of the test. Learn the remnants of answering this question. Read the common questions about the choice of vocabulary, the dates of events, the ratio of books to their author, and events to factors including them and countries to their capitals.

\section{Advantages}

The ease of their preparation and choices to engage in knowing what is on their mind, and their knowledge of being able to know them.

\section{6- Fee tests}

It is of two types

1- Giving a copy of the labels free, then students writing the parts

2- Giving two pictures and a sentence agreeing with one and asking the student to determine the method of setting the correct number (Faraj, 1980, pp. 112-115).

\section{References}

[1] Abu Asaad, Ahmed Abdel-Latif, Sami Mohammed Al-Khatatneh, and Wajdan Khalil Karaki, Principles of Psychology, 1st floor, Masirah House, Amalan, 2010.

[2] Abu Shaira, Khaled Mohammed and Thaer Ahmad Ghobari, Mental Abilities between Intelligence and Creativity, 1st Edition, 
Dar Al-Aasar Al-Alami, Amman, Jordan, 2014.

[3] Murtadha M-Hussein A-kadhim Dalia Sadiq Mahdi Al-Khateeb, Haitham K R Al-Sharifi, Ali Ibrahim Shkhair, Abdullah Hasan Jabbar*, 2018" Zinc Oxide Nanoparticles by Biological Eco-Friendly Synthesis Matrixes for Antibacterial Applications", Journal of Global Pharma Technology, 10 (8), 410-415.

[4] Abu Libdeh, Saba 'Muhammad, Principles of Psychological Measurement and Educational Evaluation of the University Student and the Arab Teacher, 1st Floor, Cooperative Printing Workers Association, Amman, 1979.

[5] The Emirate, Asaad Sharif, Persian Psychology, 1st floor, Dar Safa, Amman, 2014.

[6] Imam, Mustafa Mahmoud, Anwar Abdul Rahman, and Sabah Hassan Al-Ajili, Calendar and Measurement, 4th edition, Dar Al-Hikma, Baghdad, 1987.

[7] Khater, Mahmoud Rashid, and others, Methods of Teaching Arabic and Religious Education in the Light of Modern Educational Trends, 4th Edition, Dar AlMaarefah, 1989.

[8] Rabi`, Muhammad Shehata, Fundamentals of Psychology, 1st floor, Dar Al Masirah, Amman, 2010.

[9] Rayan, Muhammad Hashem, Thinking Skills, Speed of Intuition, and Training Facts, 1st edition, Dar Hanin, 2006.

[10] Zayour, Muhammad, Doctrines of Psychology, 1st floor, Dar Al-Hadi, Beirut, Lebanon, 2009.

[11] Saeed, Souad Jabr, Emotional Intelligence and Unlimited Energy Psychology, 1st edition, Dar Al-Sadiq, Amman, 2008.

[12] Samara, Aziz and others, Principles of Measurement and Evaluation in Education, 2nd edition, Dar Al-Fikr, Amman, 1989.

[13] Sheikh, Suleiman Al-Khudari, The Psychology of Individual Differences in
Intelligence, 1st Edition, Dar Al-Masirah, Amman, 2008.

[14] Abdul Hadi, Nabil, Educational Measurement and Evaluation and its Composition in Classroom Teaching, 2nd floor, Wael House, Amman, 2002.

[15] Obeidat, Touqan, Abu Samid, The Brain, Learning and Thinking, 3rd floor, Debono Center for Thinking Education, Amman, 2013.

[16] Al-Obaidi, Ghanem and Hanan AlJubouri, Evaluation and Measurement in Education, Shafiq Baghdad Press, 1970.

[17] Allam, Salah Al-Din Mahmoud, Educational Measurement and Evaluation in the Teaching Process, Dar Al-Fikr, Amman, 2010.

[18] Return, Ahmad Suleiman, Measurement and Evaluation in the Teaching Process, Dar Al-Amal, Irbid, 1989.

[19] The Unusual, Symbolism, Calendar, Psychological and Educational Measurement, the Egyptian Anglo Library, 1970.

[20] Faraj, Safwat, Psychometrics, Dar Al-Fikr Al-Arabi, Cairo. 1980.

[21] Katame, Youssef, The Social Intelligence of Children, 1st floor, Dar Al Masirah, Amman, 2010.

[22] Qurah, Hussein Salman, the Educational Origins in Curriculum Building, Dar AlMaarif, Egypt, 1975.

[23] Mujawar, Muhammad Salah al-Din, Examples of Objective Tests in the Arabic Language, Dar Al-Qalam, 1974.

[24] McFarland, H. s. N, Psychology and Education, 1st edition, translated by Abdul-Ali Al-Jasmani, Abdul-Wahhab AlEssa, Amal Tuaima, Dar Al-Arabia for Science, 1994.

[25] Zainb Mohammed Jassim, Shurooq Falah Hassan, Haitham KR Al-Sharifi, Abdullah Hasan Jabbar, 2019 "Synthesis of Silver Nanoparticles by Chemical Method and Investigated for Antibacterial Activity" 
Indian Journal of Public Health Research \& Development, 10 (8), 1163-1168.

[26] Nawfal, Muhammad Bakr, Scientific Applications in the Development of Thinking Using Habits of Mind, 1st Floor, Dar Al Masirah, Jordan, Amman, 2008.

[27] Wolfke, Anita, Educational Psychology, 1st floor, Dar Al-Fikr, Amman, 2010. 